\title{
On the improvement of inhibitory response control and visuospatial attention by indirect and direct adrenoceptor agonists
}

\author{
Tommy Pattij • Dustin Schetters • \\ Anton N. M. Schoffelmeer • Marcel M. van Gaalen
}

Received: 10 January 2011 / Accepted: 17 June 2011 / Published online: 19 July 2011

(C) The Author(s) 2011. This article is published with open access at Springerlink.com

\begin{abstract}
Rationale The clinical efficacy of the monoamine and noradrenaline transporter inhibitors methylphenidate and atomoxetine in attention deficit/hyperactivity disorder implicates noradrenergic neurotransmission in modulating inhibitory response control processes. Nonetheless, it is unclear which adrenoceptor subtypes are involved in these effects.

Objectives The present study aimed at investigating the effects of adrenoceptor agonists on inhibitory response control as assessed in the rodent 5-choice serial reaction time task, a widely used translational model to measure this executive cognitive function.

Results Consistent with the previous reported effects of atomoxetine, the noradrenaline transporter inhibitor desipramine improved inhibitory response control, albeit the effect size was smaller compared to that of atomoxetine. Methylphenidate exerted a bimodal effect on inhibitory response control. Interestingly, the preferential $\beta 2$-adrenoceptor agonist clenbuterol improved inhibitory response control. Moreover, clenbuterol improved visuospatial attention in the task, an effect that was also observed with the preferential $\beta 1$-adrenoceptor agonist dobutamine. By contrast, although the preferential $\alpha 1$-adrenoceptor and $\alpha 2$-adrenoceptor agonists (phenylephrine and clonidine, respectively) and the
\end{abstract}

T. Pattij $(\bowtie) \cdot$ D. Schetters · A. N. M. Schoffelmeer •

M. M. van Gaalen

Department of Anatomy and Neurosciences, Neuroscience

Campus Amsterdam, VU University Medical Center,

Van der Boechorststraat 7 ,

1081 BT Amsterdam, The Netherlands

e-mail: t.pattij@vumc.nl

Present Address:

M. M. van Gaalen

Abbott GmbH \& Co KG, CNS Pharmacology,

Ludwigshafen, Germany non-selective $\beta$-adrenoceptor agonist (isoprenaline) were found to alter inhibitory response control, this was probably secondary to the simultaneous increments in response latencies and omissions observed at effective doses.

Conclusions Taken together, these findings further strengthen the notion of noradrenergic modulation of inhibitory response control and attentional processes and particularly reveal the involvement of $\beta 2$-adrenoceptors therein.

Keywords Adrenoceptors · Attention · Clenbuterol · Impulsive behaviour $\cdot$ Noradrenaline $\cdot$ Rat

\section{Introduction}

Disturbances in inhibitory control over behaviour play a central role in the symptomatology of attention deficit/ hyperactivity disorder (ADHD; Barkley 1997; Sonuga-Barke 2005). Neuroimaging studies have greatly contributed to our growing understanding of the neural substrates of inhibitory response control processes (Aron and Poldrack 2005) and the observed structural and functional changes in the brains of ADHD patients (Valera et al. 2007). In addition to human preclinical approaches, much of our understanding of the neural substrates of inhibitory response control is derived from rodent lesion and neuropharmacological studies (Eagle et al. 2008; Pattij and Vanderschuren 2008; Winstanley et al. 2006).

Consistent with the therapeutic efficacy of the noradrenaline (NA) transporter inhibitor atomoxetine in ADHD patients (Chamberlain et al. 2007), recent studies have demonstrated that atomoxetine also improves inhibitory response control in several translational rodent models (Bari et al. 2009; Blondeau and Dellu-Hagedorn 2007; Robinson et al. 2008). Thus, these findings implicate noradrenergic neurotransmission in modulating inhibitory 
response control processes, although the precise mechanisms underlying these effects are not fully understood. Early neuronal recording experiments and subsequent studies in laboratory animals have shown that NA neurons of the locus coeruleus (LC) are phasically discharged upon exposure to novel, salient and arousing environmental stimuli (see for example, Aston-Jones and Bloom 1981; Foote et al. 1980; Sara et al. 1994). This phasic activity of the LC NA system might promote processing of these stimuli in upstream projection areas, including cortical areas, and thereby facilitate the preparation of subsequent appropriate behavioural responses. In addition, moderate tonic activity of the LC has been associated with optimal behavioural performance (AstonJones et al. 1999). In the rodent brain, frontal cortical areas importantly modulate inhibitory response control processes (Chudasama et al. 2003) and furthermore receive afferent projections from the LC (for review see, Foote and Morrison 1987). In turn, frontal cortical areas might modulate activity of the LC via efferent projections (Jodo et al. 1998; Sara and Herve-Minvielle 1995). Collectively, this has led to the view that the NA system-perhaps acting in concert with the dopaminergic system - plays a key role in optimizing behavioural responses including prefrontal cortical and executive cognitive function (Arnsten 2000; Aston-Jones and Cohen 2005; Sara 2009). Considering the current working hypothesis on noradrenergic functioning, this might also explain the therapeutic efficacy of methylphenidate in ADHD, which has been shown to enhance NA levels at low doses (Berridge et al. 2006; Devilbiss and Berridge 2006).

To date, little is known with regard to the involvement of different adrenoceptor subtypes in inhibitory response control, although previous work in rodents suggested a functional role of $\alpha$-adrenoceptors (Milstein et al. 2007; Puumala et al. 1997; Ruotsalainen et al. 1997; Sirvio et al. 1994). Generally, these studies suggest $\alpha 1$-adrenoceptor involvement, as an agonist of this adrenoceptor subtype was found to selectively improve inhibitory response control (Puumala et al. 1997). Moreover, $\alpha 2$-adrenoceptor agonists also ameliorate inhibitory response control, albeit these beneficial effects were only observed at doses that simultaneously impaired somatomotor performance (Milstein et al. 2007; Ruotsalainen et al. 1997; Sirvio et al. 1994). Thus, these preclinical findings with $\alpha$-adrenoceptor agonists in part support the clinical beneficial effects of the $\alpha 2$ adrenoceptor agonists clonidine and guanfacine in ADHD (Arnsten et al. 2007). Interestingly, in both healthy volunteers and rats, the $\alpha 2$-adrenoceptor antagonist yohimbine has been demonstrated to impair inhibitory response control (Sun et al. 2010; Swann et al. 2005). To our knowledge, $\beta$ adrenoceptor involvement in inhibitory response control has not been investigated in detail before. Therefore, further dissecting the contribution of specific adrenoceptors therein could provide novel insights into the mechanism of action of atomoxetine and methylphenidate. To that end, we investigated the effects of various selective $\alpha$-adrenoceptor and $\beta$ adrenoceptor agonists in addition to those of indirect agonists on inhibitory response control in rats. More specifically, we tested the effects of the monoamine reuptake inhibitor methylphenidate, the noradrenaline reuptake inhibitor desipramine, the $\alpha 1$-adrenoceptor and $\alpha 2$-adrenoceptor agonists phenylephrine and clonidine, the non-selective $\beta$-adrenoceptor agonist isoprenaline and lastly the $\beta 1$ adrenoceptor and $\beta 2$-adrenoceptor agonists, dobutamine and clenbuterol. To assess drug effects, rats were trained in the 5-choice serial reaction time task (5CSRTT), which is a widely employed rodent operant cognitive task adopted from the human continuous performance task that measures aspects of visuospatial attention as well as inhibitory response control (see for reviews, Bari et al. 2008; Robbins 2002).

\section{Material and methods}

\section{Subjects}

In total, 60 male Wistar rats were obtained from Harlan CPB (Horst, The Netherlands). At the start of the experiments, animals were 12 weeks old, weighed approximately $250 \mathrm{~g}$ and were housed in pairs in macrolon cages $(42.5 \times 26.6 \times 18.5 \mathrm{~cm}$; $l \times w \times h)$ under a reversed 12-h light/dark cycle (lights on at 7:00 p.m.) at controlled room temperature $\left(21 \pm 2^{\circ} \mathrm{C}\right)$ and relative humidity of $60 \pm 15 \%$. Animals were maintained at approximately $90 \%$ of their free-feeding weight, starting 1 week prior to the beginning of the experiments by restricting the amount of standard rodent food pellets (Harlan Teklad Global Diet, Blackthorn, UK). Water was available ad libitum throughout the entire experiment. All experiments were conducted with the approval of the animal ethical committee of the Vrije Universiteit, Amsterdam, the Netherlands.

\section{Apparatus}

Experiments were conducted in identical rat five hole nose poke operant chambers with stainless steel grid floors (MEDNPW-5L, Med Associates Inc., St. Albans, VT, USA) housed in sound-insulating and ventilated cubicles. Set in the curved wall of each box was an array of five holes. Each nose poke unit was equipped with an infrared detector and a yellow light emitting diode stimulus light. Rodent food pellets (45 mg, Formula P, Bio-Serv, Frenchtown, USA) could be delivered at the opposite wall via a dispenser and a white house light could illuminate the chamber. A computer equipped with MED-PC version 1.17 (Med Associates Inc.) controlled experimental sessions and recorded data. The animals were tested once daily from Monday until Friday during the dark phase of the light/dark cycle. 
Behavioural procedure

To habituate animals to the operant chambers, rats were exposed to the operant chambers for $20 \mathrm{~min}$ with the houselight on and the food cup containing three food pellets for two consecutive sessions. Subsequently, in the next two sessions, pellets (100 per session) were delivered with an average delay of $15 \mathrm{~s}$ to allow the animals to associate the sound of pellet delivery with reward. Following this, the rats were trained in the 5CSRTT paradigm. A detailed description of the 5CSRTT behavioural procedure in our laboratory has been provided previously (Van Gaalen et al. 2006a). In short, rats were trained to detect and respond to a brief visual stimulus in one of five nose poke units in order to obtain a food reward. Each session terminated after 100 trials or $30 \mathrm{~min}$, whichever occurred first. Initially, the duration of this stimulus was $32 \mathrm{~s}$ and was gradually decreased to $1 \mathrm{~s}$ over sessions until animals reached stable baseline performance (accuracy $>80 \%$ correct choice and $<20 \%$ errors of omission, for at least five consecutive sessions). Responding during stimulus presentation or within the limited hold (LH) period of $2 \mathrm{~s}$ was counted as a correct response. Incorrect, premature responses during the fixed 5-s intertrial interval and errors of omission (no responses or a response after the $\mathrm{LH}$ ) did not lead to the delivery of a food reward and resulted in a 5-s time out period during which the houselight was extinguished, whereas perseverative responses, i.e. repeated responding during the presentation of the stimulus, were measured but did not have any programmed consequences. Two different measures of inhibitory control were measured, namely (1) the percentage of premature responses before stimulus onset, calculated as [number of premature responses / (correct + incorrect + omitted trials) $] \times 100$ and (2) the percentage of perseverative responses into the stimulus unit after correct choice, a measure of compulsive behaviour, calculated as [number of perseverative responses / (correct + incorrect + omitted trials $)] \times 100$. In addition, the following other behavioural parameters were measured that reflect task performance, namely (3) accurate choice, i.e. percentage correct responses calculated as [number correct trials / (correct + incorrect trials) $] \times 100$; (4) latency to make a correct choice, i.e. the mean time between stimulus onset and nose poke in the illuminated unit; (5) omission errors, i.e. the percentage of omitted trials during a session calculated as [number of omitted trials / (correct + incorrect + omitted trials) $] \times 100$ and (6) feeder latency, i.e. the latency to collect a pellet following correct choice.

\section{Drugs}

Methylphenidate hydrochloride (Fagron, Nieuwerkerk a/d IJssel, Netherlands), clenbuterol hydrochloride, desipra- mine hydrochloride, dobutamine hydrochloride, phenylephrine hydrochloride (Sigma-Aldrich, St. Louis, MO, USA), clonidine hydrochloride (Boehringer Ingelheim, Ingelheim am Rhein, Germany) and isoprenaline sulphate (ACF Chemiefarma, Maarssen, the Netherlands) were dissolved in sterile saline. All drugs were injected $30 \mathrm{~min}$ before testing, with the exception of methylphenidate, isoprenaline and clenbuterol that were injected $20 \mathrm{~min}$ before testing. Desipramine (dose range, $1-10 \mathrm{mg} / \mathrm{kg}$ ), clenbuterol (dose range, $0.01-0.1 \mathrm{mg} / \mathrm{kg}$ ), dobutamine (dose range, $1-6 \mathrm{mg} / \mathrm{kg}$ ) and phenylephrine (dose range, $0.3-3 \mathrm{mg} / \mathrm{kg}$ ) were injected intraperitoneally, clonidine (dose range, $0.01-0.03 \mathrm{mg} / \mathrm{kg}$ ) and isoprenaline (dose range, $0.1-1 \mathrm{mg} / \mathrm{kg}$ ) were injected subcutaneously and methylphenidate (dose range, $1-10 \mathrm{mg} / \mathrm{kg}$ ) was administered orally via oral gavage. In group $1(n=14)$, the order of testing drugs was (1) desipramine, (2) clonidine and (3) phenylephrine. In group $2(n=14)$, isoprenaline was tested; in group $3(n=16)$, methylphenidate was tested, and in group $4(n=16)$, dobutamine and clenbuterol were tested. Drugs were freshly prepared before testing and injected in a volume of $1 \mathrm{ml} / \mathrm{kg}$ body weight according to a Latin square within-subjects design on Tuesdays and Fridays with baseline training sessions on the other weekdays. Drug doses were based on previous reports employing instrumental behaviour paradigms (Arnsten and Dudley 2005; Munzar and Goldberg 1999; O'Donnell 1990; Van Gaalen et al. 2006b).

\section{Statistical analyses}

Data were subjected to repeated measures analysis of variance (ANOVA) with drug dose as within-subjects variable using the Statistical Package for the Social Sciences version 14 (SPSS Inc., Chicago, IL, USA). The homogeneity of variance across groups was determined using Mauchly's tests for equal variances and in case of violation of homogeneity, Huynh-Feldt epsilon $(\varepsilon)$ adjusted degrees of freedom were applied and the resulting more conservative probability values were depicted and used for subsequent analyses. In case of statistically significant main effects, further post hoc comparisons were conducted using Newman-Keuls multiple comparison tests. The level of probability for statistically significant effects was set at 0.05 .

\section{Results}

Baseline performance

Drug testing commenced upon stable baseline performance in the 5CSRTT. Repeated measures ANOVA of the five last baseline training sessions revealed that in all groups behavioural performance had stabilized before drug testing in terms of the percentage of accurate choice [group $1, F(4,52)=1.40$, 
$p=0.25$; group $2, F(4,52)=0.33, p=0.85$; group $3, F(4,60)=$ $0.63, \varepsilon=0.43, p=0.52$; group $4, F(4,60)=1.25, p=0.30]$, the percentage of omission errors [group 1, $F(4,52)=1.37, p=$ 0.26 ; group $2, F(4,52)=2.06, \varepsilon=0.71, p=0.12$; group 3 , $F(4,60)=0.65, p=0.63$; group $4, F(4,60)=1.01, \varepsilon=0.78, p=$ $0.40]$ and the percentage of premature responding [group 1 , $F(4,52)=1.14, p=0.35$; group $2, F(4,52)=0.30, \varepsilon=0.60, p=$ 0.75 ; group $3, F(4,60)=1.06, \varepsilon=0.59, p=0.37$; group 4 , $F(4,60)=1.79, \varepsilon=0.59, p=0.18]$. Furthermore, during testing of all separate drugs, repeated measures ANOVA on the intervening pre-drug baseline training sessions revealed that behavioural performance on accurate choice, percentage omissions and percentage premature responding did not shift and remained stable (all $p>0.05$; data not shown).

\section{Methylphenidate}

Methylphenidate had a biphasic effect on the percentage premature responses [Fig. 1a; $F(3,45)=15.72, \varepsilon=0.47, p<$ $0.001]$ and strongly tended to decrease premature responding at the low dose ( $1 \mathrm{mg} / \mathrm{kg} ; p=0.055)$, whereas it increased this parameter at the highest dose $(10 \mathrm{mg} / \mathrm{kg} ; p=0.002)$ compared to vehicle. Accurate choice was decreased by methylphenidate [Fig. 1b; $F(3,45)=5.33, p=0.003$ ], and methylphenidate also speeded correct response latencies [Fig. 1c; $F(3,45)=3.28, p=0.029]$. Further comparisons revealed that only $10 \mathrm{mg} / \mathrm{kg}$ methylphenidate impaired visuospatial attention $(p=0.001)$ and speeded response latencies $(p=0.035)$ compared to the vehicle. The percentage of omissions was not altered by methylphenidate [Fig. 1d; $F(3,45)=0.63, p=0.60]$ or was the percentage of perseverative responses and latency to collect reward after correct choice [Table 1; $F(3,45)=0.61, \varepsilon=0.53, p=0.51$ and $F(3,45)=$ $0.40, \varepsilon=0.73, p=0.69$, respectively].

\section{Desipramine}

The selective NA reuptake inhibitor desipramine dose dependently decreased the percentage of premature responses [Fig. 2a; $F(3,39)=8.51, p<0.001$ ] and further analyses revealed that compared to vehicle this was the case for both the 3 and $10 \mathrm{mg} / \mathrm{kg}$ dose of desipramine ( $p=0.022$ and $p<0.001$, respectively). In addition to the effects of desipramine on premature responding, desipramine increased correct response latencies [Fig. $2 \mathrm{c} ; F(3,39)=4.46$, $p=0.009]$ and the percentage of omissions [Fig. $2 \mathrm{~d} ;(3,39)=$ $6.85, \varepsilon=0.85, p=0.002]$. Further analyses revealed that only $10 \mathrm{mg} / \mathrm{kg}$ desipramine significantly increased response latencies and omissions compared to the vehicle $(p=0.005$ and $p<0.001$, respectively). Likewise, the latency to collect reward after correct choice was increased by desipramine [Table 1; $F(3,39)=3.37, \varepsilon=0.79, p=0.04]$. Further analyses
Fig. 1 Methylphenidate exerts a bimodal effect on the percentage premature responses (a), decreases the percentage correct choice (b), shortens correct response latency (c) and does not affect the percentage omissions (d) in the 5CSRTT. All data are expressed as mean $\pm \mathrm{SEM}$. ${ }^{*} p<0.05$ and $* * p<0.005$ compared to vehicle treatment

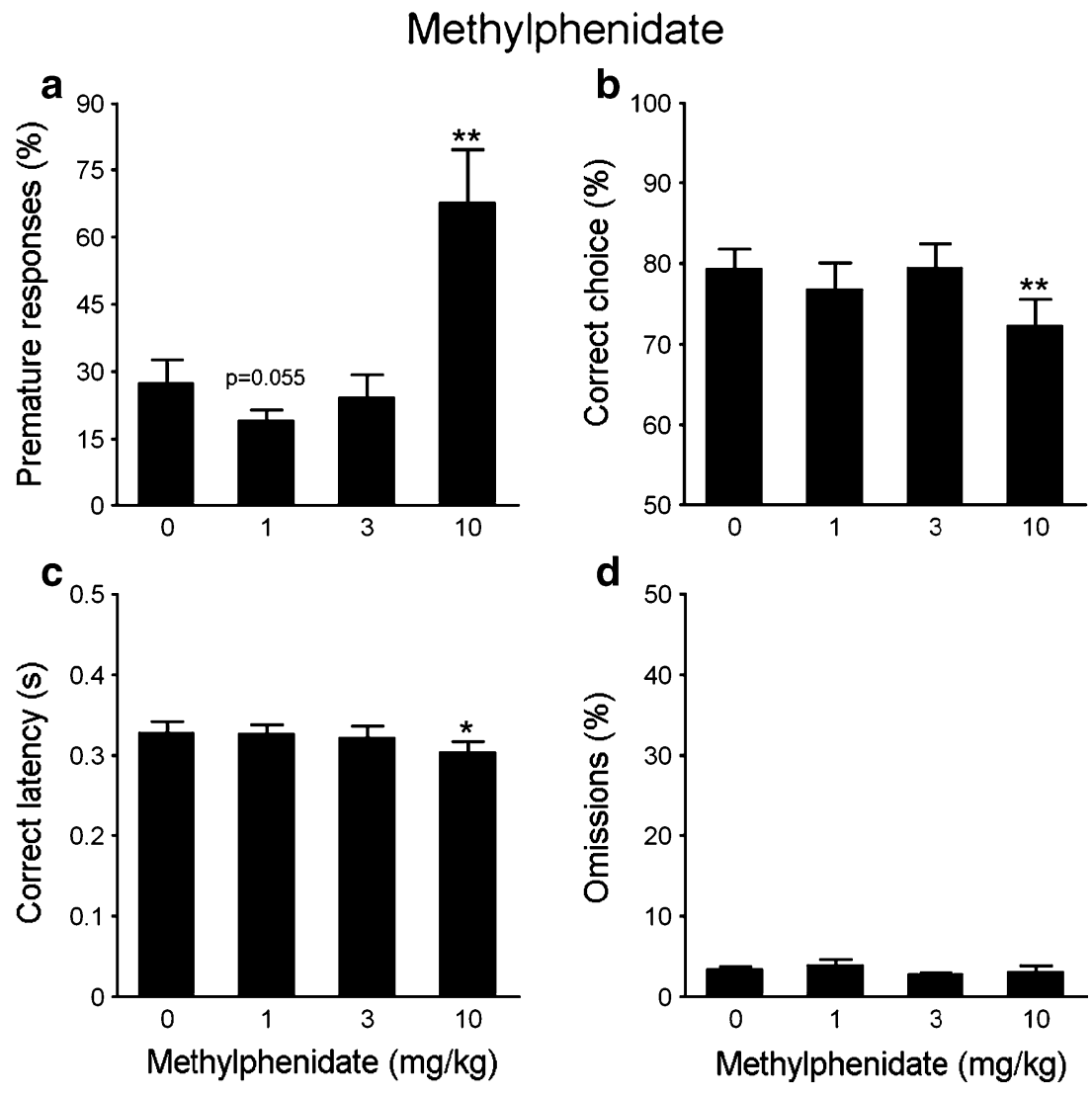


Table 1 Effects of indirect and direct adrenoceptor agonists on the percentage of perseverative responses and latencies to collect food reward after correct choice

\begin{tabular}{|c|c|c|c|}
\hline Drug & $\begin{array}{l}\text { Dose } \\
(\mathrm{mg} / \mathrm{kg})\end{array}$ & $\begin{array}{l}\text { Perseverative } \\
\text { responses (\%) }\end{array}$ & $\begin{array}{l}\text { Feeder } \\
\text { latency }(\mathrm{s})\end{array}$ \\
\hline \multirow[t]{4}{*}{ Methylphenidate } & 0 & $3.81 \pm 1.16$ & $0.90 \pm 0.04$ \\
\hline & 1.0 & $3.69 \pm 1.13$ & $0.92 \pm 0.05$ \\
\hline & 3.0 & $5.69 \pm 1.63$ & $0.94 \pm 0.06$ \\
\hline & 10.0 & $5.12 \pm 2.23$ & $0.88 \pm 0.06$ \\
\hline \multirow[t]{4}{*}{ Desipramine } & 0 & $6.64 \pm 1.50$ & $0.99 \pm 0.07$ \\
\hline & 1.0 & $9.00 \pm 2.26$ & $1.23 \pm 0.15^{*}$ \\
\hline & 3.0 & $8.93 \pm 1.38$ & $1.06 \pm 0.06$ \\
\hline & 10.0 & $9.86 \pm 1.61$ & $1.25 \pm 0.12^{*}$ \\
\hline \multirow[t]{4}{*}{ Phenylephrine } & 0 & $7.43 \pm 1.48$ & $0.98 \pm 0.07$ \\
\hline & 0.3 & $7.50 \pm 1.73$ & $1.08 \pm 0.16$ \\
\hline & 1.0 & $10.21 \pm 2.23$ & $0.91 \pm 0.04$ \\
\hline & 3.0 & $7.36 \pm 1.58$ & $1.15 \pm 0.10$ \\
\hline \multirow[t]{3}{*}{ Clonidine } & 0 & $9.21 \pm 2.25$ & $1.09 \pm 0.10$ \\
\hline & 0.01 & $9.86 \pm 2.41$ & $1.36 \pm 0.22$ \\
\hline & 0.03 & $4.21 \pm 0.71^{*}$ & $1.19 \pm 0.06$ \\
\hline \multirow[t]{4}{*}{ Isoprenaline } & 0 & $5.29 \pm 2.53$ & $0.98 \pm 0.05$ \\
\hline & 0.1 & $2.64 \pm 0.84$ & $1.10 \pm 0.07$ \\
\hline & 0.3 & $4.21 \pm 1.44$ & $1.07 \pm 0.05$ \\
\hline & 1.0 & $4.57 \pm 2.08$ & $1.19 \pm 0.08^{*}$ \\
\hline \multirow[t]{4}{*}{ Dobutamine } & 0 & $12.54 \pm 7.24$ & $1.21 \pm 0.13$ \\
\hline & 1.0 & $9.23 \pm 4.10$ & $1.31 \pm 0.12$ \\
\hline & 3.0 & $8.08 \pm 2.70$ & $1.16 \pm 0.11$ \\
\hline & 6.0 & $4.77 \pm 1.67$ & $1.25 \pm 0.13$ \\
\hline \multirow[t]{4}{*}{ Clenbuterol } & 0 & $7.53 \pm 2.14$ & $1.27 \pm 0.16$ \\
\hline & 0.01 & $7.07 \pm 1.75$ & $1.33 \pm 0.14$ \\
\hline & 0.03 & $8.60 \pm 1.65$ & $1.45 \pm 0.13$ \\
\hline & 0.1 & $6.40 \pm 1.39$ & $1.82 \pm 0.25$ \\
\hline
\end{tabular}

Drug doses are expressed in milligrams per kilogram and all data are expressed as the mean $\pm \mathrm{SEM}$

${ }^{*} p<0.05$ versus vehicle

showed that 1 and $10 \mathrm{mg} / \mathrm{kg}$ desipramine increased collection latencies compared to vehicle ( $p=0.049$ and $p=$ 0.008 , respectively). Accurate choice was not affected by desipramine [Fig. 2b; $F(3,39)=0.31, p=0.82$ ] or was the percentage of perseverative nose pokes after correct choice [Table $1 ; F(3,39)=0.85, p=0.48]$.

\section{Phenylephrine}

The $\alpha 1$-adrenoceptor agonist phenylephrine decreased the percentage of premature responses [Fig. 3a; $F(3,39)=6.97$, $p=0.001]$ and this occurred only at the dose of $3.0 \mathrm{mg} / \mathrm{kg}$ compared to the vehicle $(p<0.001)$. Phenylephrine also increased the latency to make a correct choice [Fig. 3c;
$F(3,39)=10.72, \varepsilon=0.49, p=0.002]$ and increased the percentage of omissions [Fig. $3 \mathrm{~d} ; F(3,39)=4.77, \varepsilon=0.55$, $p=0.025]$. Further comparisons showed that $3.0 \mathrm{mg} / \mathrm{kg}$ phenylephrine significantly slowed response speed and increased omission rate compared to vehicle ( $p=0.007$ and $p=$ 0.016 , respectively). Moreover, phenylephrine significantly improved accurate choice [Fig. 3b; $F(3,39)=2.92, p=0.046$ ]. Further comparisons revealed that the high dose of $3.0 \mathrm{mg} / \mathrm{kg}$ phenylephrine tended to improve accurate choice compared to the vehicle, yet this effect did not reach statistical significance $(p=0.063)$. The percentage of perseverative nose pokes and latency to collect reward after correct choice were not altered by phenylephrine [Table $1 ; F(3,39)=1.52, p=0.22$ and $F(3,39)=2.16, \varepsilon=0.65, p=0.14$, respectively].

\section{Clonidine}

The $\alpha 2$-adrenoceptor agonist clonidine reduced the percentage of premature responses [Fig. 3e; $F(2,26)=8.47, p=$ $0.001]$, and further analyses revealed that both doses decreased premature responding compared to vehicle (both $p=0.008)$. In addition, clonidine dose dependently lengthened the latency to make a correct response [Fig. 3g; $F(2,26)=40.54, p<0.001]$ at both doses compared to the vehicle (both $p<0.001$ ). Clonidine also dose dependently increased the percentage of omissions [Fig. $3 \mathrm{~h} ; F(2,26)=$ $42.25, p<0.001]$, and both doses increased omission rate compared to vehicle (both $p<0.001$ ). The percentage of perseverative responses after correct choice was significantly reduced by clonidine [Table $1 ; F(2,26)=3.68, p=0.039$ ] Further analyses showed that only $0.03 \mathrm{mg} / \mathrm{kg}$ clonidine reduced the number of persevative nose pokes after correct choice compared to vehicle treatment $(p=0.031)$. Clonidine did neither affect accurate choice [Fig. 3f; $F(2,26)=1.29$, $p=0.29$ ] nor the latency to collect reward after correct choice [Table 1; $F(2,26)=1.40, \varepsilon=0.63, p=0.26]$.

Isoprenaline

The non-selective $\beta$-adrenoceptor agonist isoprenaline reduced the percentage of premature responses [Fig. 4a; $F(3,39)=3.98, p=0.014]$. Further analyses showed that $0.3 \mathrm{mg} / \mathrm{kg}$ isoprenaline reduced premature responding compared to vehicle $(p=0.024)$. Isoprenaline dose dependently lengthened the latency to make a correct response [Fig. $4 \mathrm{c} ; F(3,39)=17.11, p<0.001]$ and further comparisons revealed that all doses lengthened the latency compared to the vehicle $(0.1$ and $1.0 \mathrm{mg} / \mathrm{kg}$, both $p<0.001$ and $0.3 \mathrm{mg} / \mathrm{kg}, p=$ 0.002 ). The percentage of omissions was increased by isoprenaline [Fig. $4 \mathrm{~d} ; F(3,39)=6.80, p=0.001]$ at all doses compared to vehicle $(0.1 \mathrm{mg} / \mathrm{kg}, p=0.002 ; 0.3 \mathrm{mg} / \mathrm{kg}, p=$ 0.003 and $1.0 \mathrm{mg} / \mathrm{kg}, p<0.001)$. Furthermore, isoprenaline also lengthened the latency to collect reward after correct 
Fig. 2 The noradrenaline reuptake inhibitor desipramine decreases the percentage premature responses (a), does not affect the percentage correct choice (b), and increases both correct response latency (c) and the percentage omissions (d) in the 5CSRTT. All data are expressed as mean \pm SEM. ${ }^{*} p<0.05$ and ${ }^{*} p<00.005$ compared to vehicle treatment

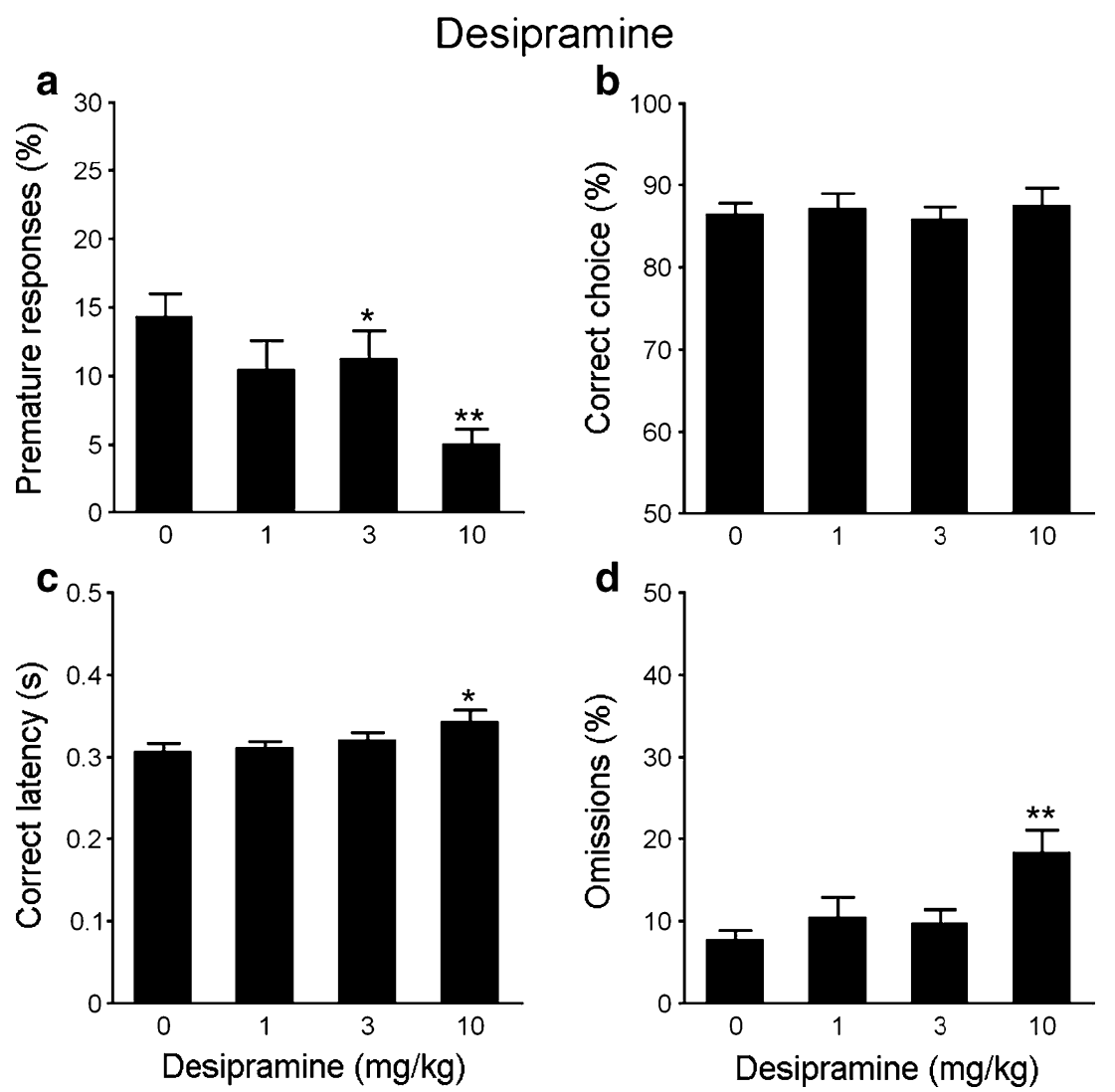

choice [Table $1 ; F(3,39)=4.12, \varepsilon=0.70, p=0.026$ ], and this was only the case at $1.0 \mathrm{mg} / \mathrm{kg}$ compared to the vehicle ( $p=$ 0.023). Accurate choice [Fig. 4b; $F(3,39)=1.04, p=0.39$ ] and the percentage of perseverative responses after correct choice [Table $1 ; F(3,39)=0.76, p=0.53$ ] were not affected by isoprenaline.

\section{Dobutamine}

Three animals were excluded from all analyses, as these individuals consistently omitted over 50 trials in all drug dose treatments including vehicle treatment. Challenges with the $\beta 1$-adrenoceptor agonist dobutamine tended to decrease the percentage of premature responses, although the main dose effect did not reach statistical significance [Fig. 5a; $F(3,36)=3.21, \varepsilon=0.66, p=0.059]$. Dobutamine did increase the percentage of omissions [Fig. $5 \mathrm{~d} ; F(3,36)=$ $4.25, p=0.011]$ and further comparisons revealed that only $3 \mathrm{mg} / \mathrm{kg}$ dobutamine increased the omission rate compared to the vehicle $(p=0.002)$. In addition, dobutamine improved accurate choice [Fig. 5b; $F(3,36)=4.14, p=$ 0.013 ], and further analyses revealed that $6 \mathrm{mg} / \mathrm{kg}$ dobutamine improved visuospatial attention compared to the vehicle $(p=0.001)$. The latencies to make a correct choice [Fig. 5c; $F(3,36)=2.06, p=0.12]$ and collect food reward after correct choice [Table $1 ; F(3,36)=1.06, \varepsilon=0.57, p=0.36$ ] were not altered by dobutamine or was the percentage of perseverative responses [Table $1 ; F(3,36)=1.53, \varepsilon=0.47$, $p=0.24]$.

\section{Clenbuterol}

One animal was excluded from all analyses due to a consistent high number of omissions during vehicle and drug treatments ( $>50$ trials). The administration of the selective $\beta 2$-adrenoceptor agonist clenbuterol reduced the percentage of premature responses [Fig. 5e; $F(3,42)=6.48$, $\varepsilon=0.73, p=0.004$ ], and further comparisons showed that all doses of clenbuterol decreased premature responding compared to vehicle $(0.01 \mathrm{mg} / \mathrm{kg}, p=0.036 ; 0.03 \mathrm{mg} / \mathrm{kg}$, $p=0.008$ and $0.1 \mathrm{mg} / \mathrm{kg}, p=0.009$ ). Likewise, clenbuterol lengthened the latency to make a correct response [Fig. $5 \mathrm{~g} ; \quad F(3,42)=10.31, \varepsilon=0.81, p<0.001]$ at the $0.1 \mathrm{mg} / \mathrm{kg}$ dose compared to the vehicle $(p<0.001)$. Clenbuterol also increased the percentage of omissions [Fig. 5h; $F(3,42)=19.16, \varepsilon=0.38, p<0.001]$ and this also only occurred at the highest dose of $0.1 \mathrm{mg} / \mathrm{kg}$ compared to the vehicle $(p=0.001)$. Accurate choice was dose dependently improved by clenbuterol [Fig. 5f; $F(3,42)=$ 6.35, $p=0.001]$, and both 0.03 and $0.1 \mathrm{mg} / \mathrm{kg}$ clenbuterol increased the percentage correct choice compared to vehicle ( $p=0.002$ and $p=0.005$, respectively). The per- 
Fig. 3 The preferential $\alpha 1$-adrenoceptor and $\alpha 2$-adrenoceptor agonists phenylephrine and clonidide decrease the percentage premature responses (a, e), do not affect the percentage correct choice $(\mathbf{b}, \mathbf{f})$, and increase correct response latency $(\mathbf{c}, \mathbf{g})$ and the percentage omissions $(\mathbf{d}, \mathbf{h})$ in the 5CSRTT. All data are expressed as mean \pm SEM. $* p<0.05$ and ${ }^{* *} p<0.005$ compared to vehicle treatment
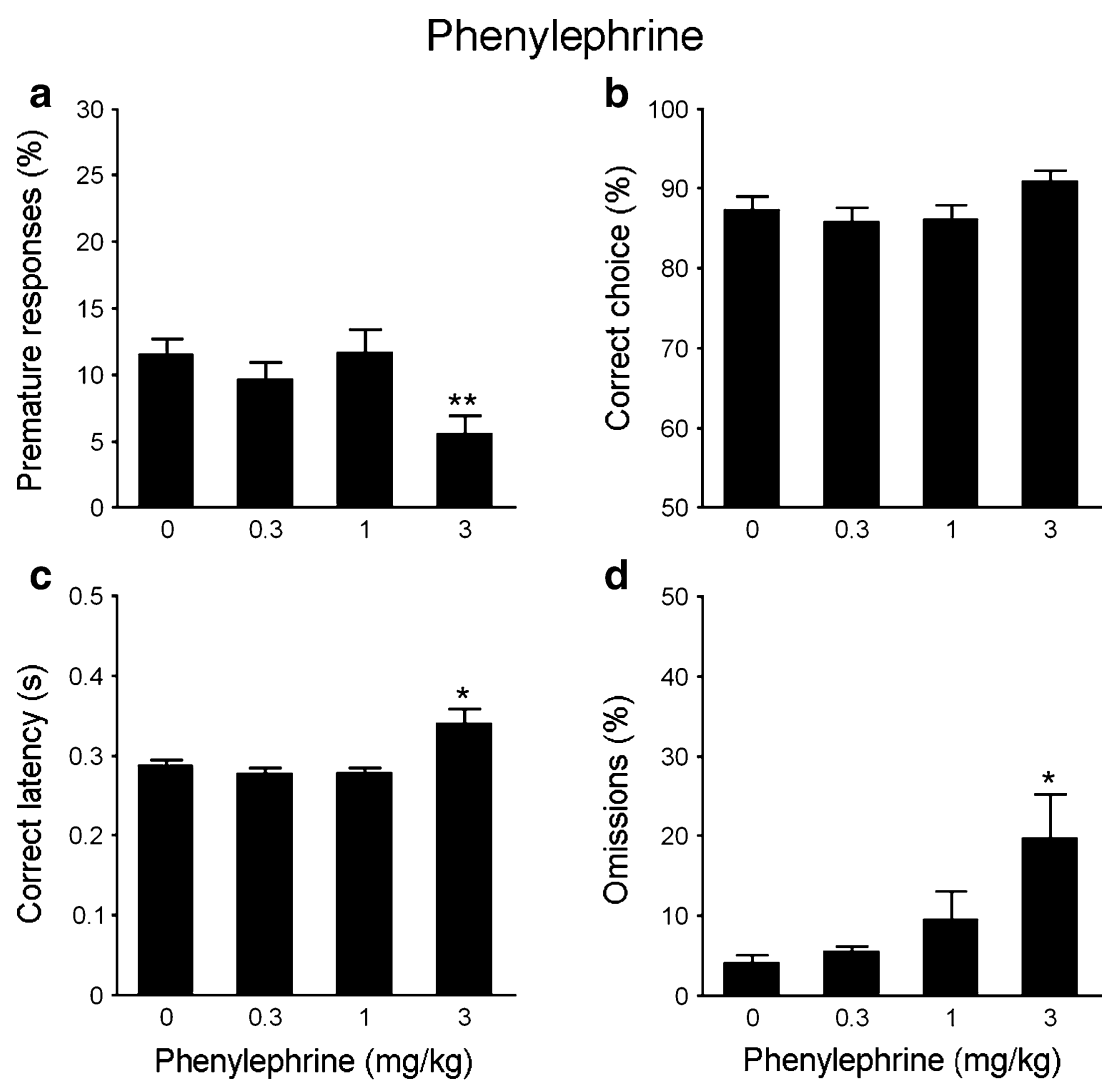

Clonidine
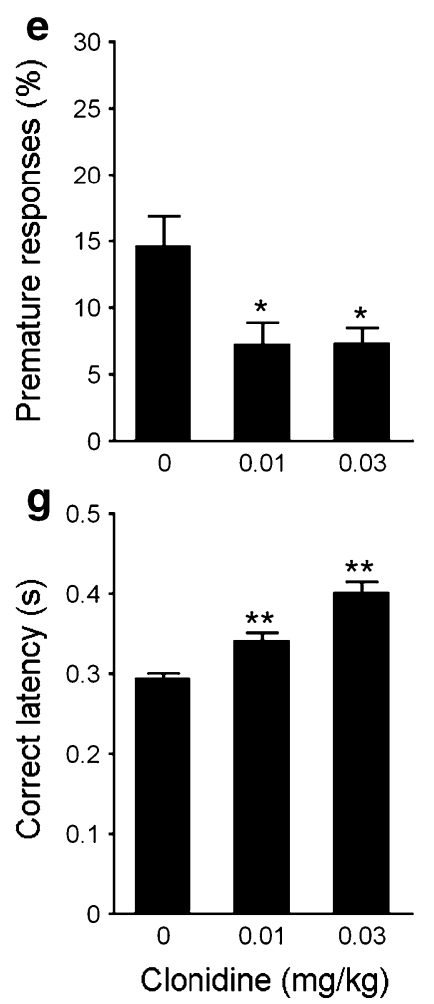
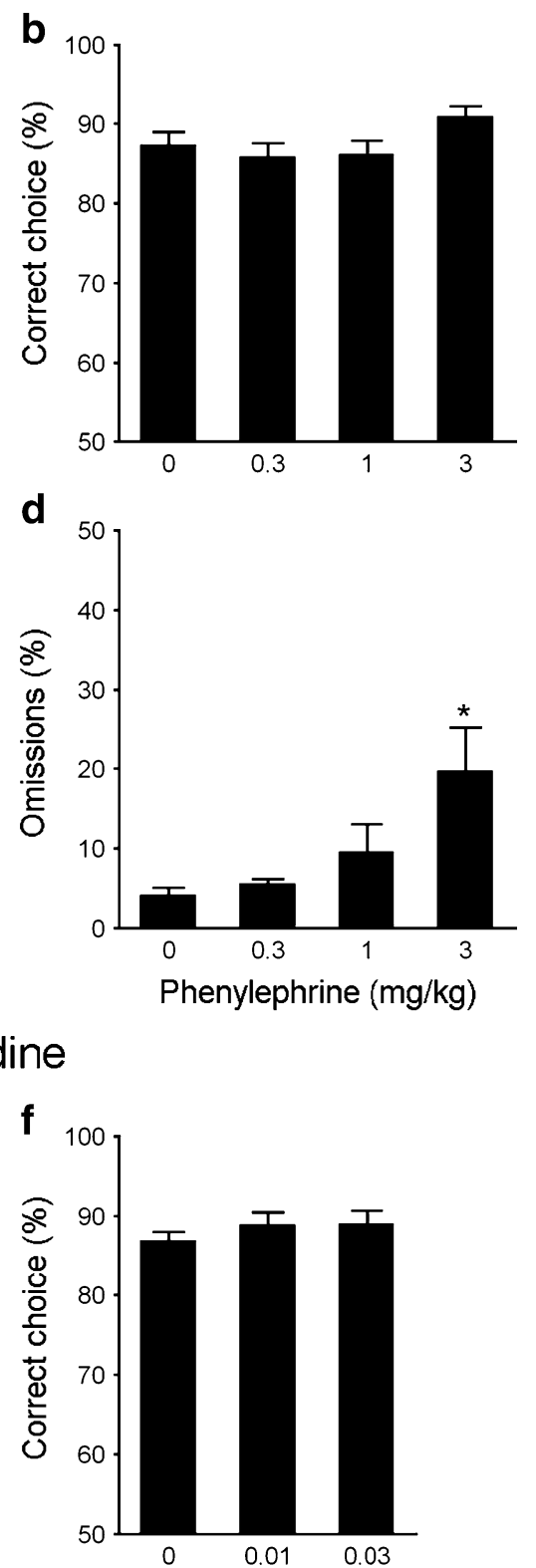

h

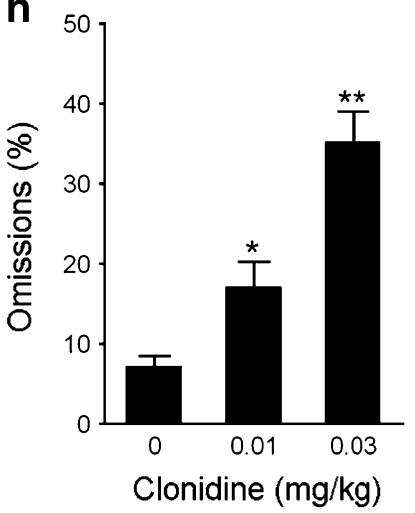

centage of perseverative responses after correct choice and the latency to collect food reward were not affected by clenbuterol [Table 1; $F(3,42)=0.45, p=0.72$ and $F(3,42)=$ $2.82, \varepsilon=0.51, p=0.094$; respectively]. 
Fig. 4 The non-selective $\beta$ adrenoceptor agonist isoprenaline decreases the percentage premature responses (a), does not affect the percentage correct choice (b), and increases correct response latency (c) and percentage of omissions (d) in the 5CSRTT. All data are expressed as mean \pm SEM. ${ }^{*} p<0.05$ and $* * p<0.005$ compared to vehicle treatment
Isoprenaline
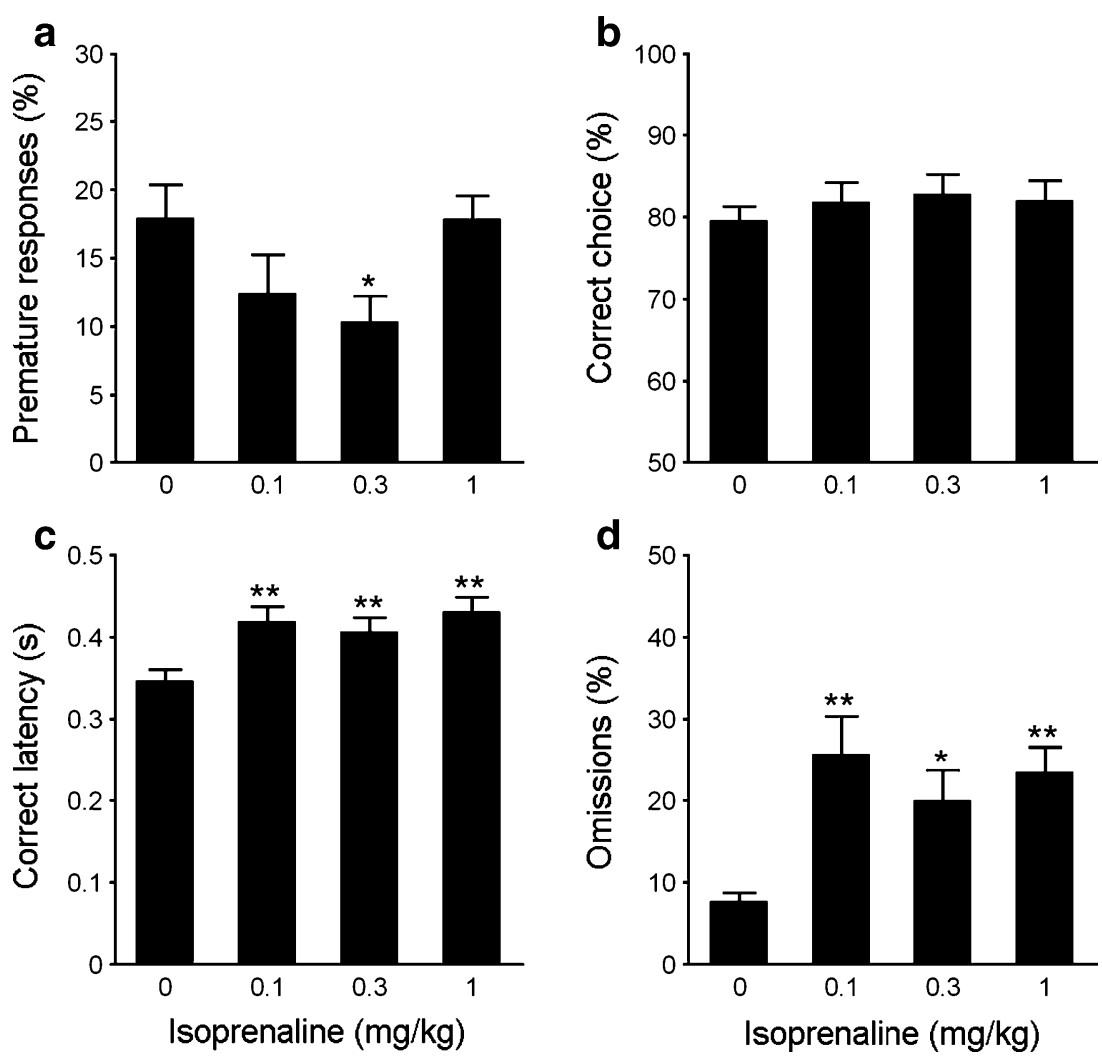

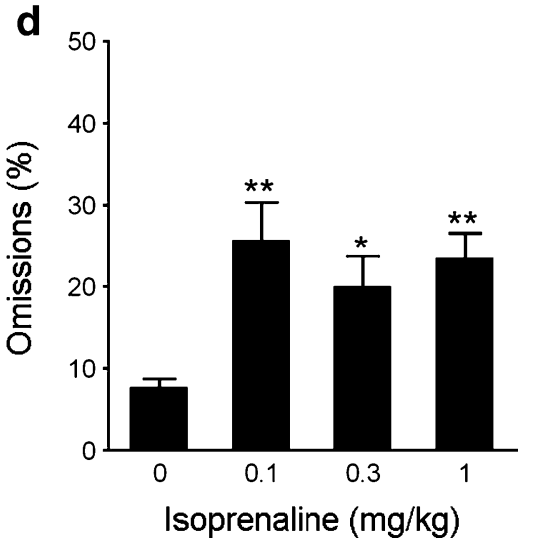

\section{Discussion}

The present data are consistent with a functional role of noradrenergic transmission in inhibitory response control processes. In particular, the NA reuptake inhibitor desipramine was found to improve inhibitory response control at a dose that did not affect somatomotor activity. Likewise, methylphenidate seemed to have a similar effect at a low dose, whereas opposite effects were found at higher doses that impaired inhibitory response control by increasing premature responding. Both the selective $\alpha 1$-adrenoceptor and $\alpha 2$-adrenoceptor agonists (phenylephrine and clonidine) and the non-selective $\beta$-adrenoceptor agonist (isoprenaline) tested in the present study were found to alter inhibitory control, but these effects were only observed at doses that simultaneously increased response latencies and omission rate. By contrast, the selective $\beta 2$-adrenoceptor agonist clenbuterol, and to a lesser extent the $\beta 1$-agonist dobutamine, had beneficial effects on inhibitory control and visuospatial attention at doses that did not alter other behavioural parameters in the task.

The current findings with methylphenidate confirm earlier data indicating that methylphenidate increases impulsivity in the 5CSRTT (Milstein et al. 2010; Navarra et al. 2008; Puumala et al. 1996; Van den Bergh et al. 2006). Thus, in the present study, oral administration of $10 \mathrm{mg} / \mathrm{kg}$ methylphenidate also robustly increased premature responding. As methylphenidate increases monoamine neurotransmission by inhibiting the activity of monoamine transporter proteins (Rothman and Baumann 2003), it has been well established that methylphenidate enhances both dopaminergic and noradrenergic transmission in corticostriatal brain regions (Gerasimov et al. 2000; Kuczenski and Segal 1997). In support of this, a large body of evidence has demonstrated that elevating dopamine (DA) signalling by means of the psychostimulant amphetamine or the selective DA reuptake inhibitor GBR12909 robustly increases premature responding in the 5CSRTT (Cole and Robbins 1987; Harrison et al. 1997; Pattij et al. 2007; Van Gaalen et al. 2006a), possibly explaining the current observations with $10 \mathrm{mg} / \mathrm{kg}$ methylphenidate. By contrast, in the present study, a low oral dose of methylphenidate $(1 \mathrm{mg} / \mathrm{kg}$ ) tended to reduce the number of premature responses $(p=0.055)$. Interestingly, comparable low doses of methylphenidate have been shown to preferentially increase the extracellular levels of NA over DA in the prefrontal cortex and simultaneously improve sustained attention and working memory (Berridge et al. 2006). This could explain the beneficial effect of the low dose methylphenidate on inhibitory control in the current study. Indeed, enhancing NA transmission by the NA reuptake inhibitor atomoxetine improves inhibitory response control 
Fig. 5 Effects of the $\beta 1$ adrenoceptor agonist dobutamine and $\beta 2$-adrenoceptor agonist clenbuterol on the percentage premature responses (a, e), percentage correct choice $(\mathbf{b}, \mathbf{f})$, correct response latency $(\mathbf{c}, \mathbf{g})$ and the percentage omissions $(\mathbf{d}, \mathbf{h})$ as measured in the 5CSRTT. Both dobutamine and clenbuterol improve visuospatial attention at doses that do not alter response latency or the percentage of omitted trials. In addition, clenbuterol exerts a beneficial effect on inhibitory response control by reducing the percentage premature responding. All data are expressed as mean \pm SEM. ${ }^{*} p<0.05$ and $* * p<0.005$ compared to vehicle treatment
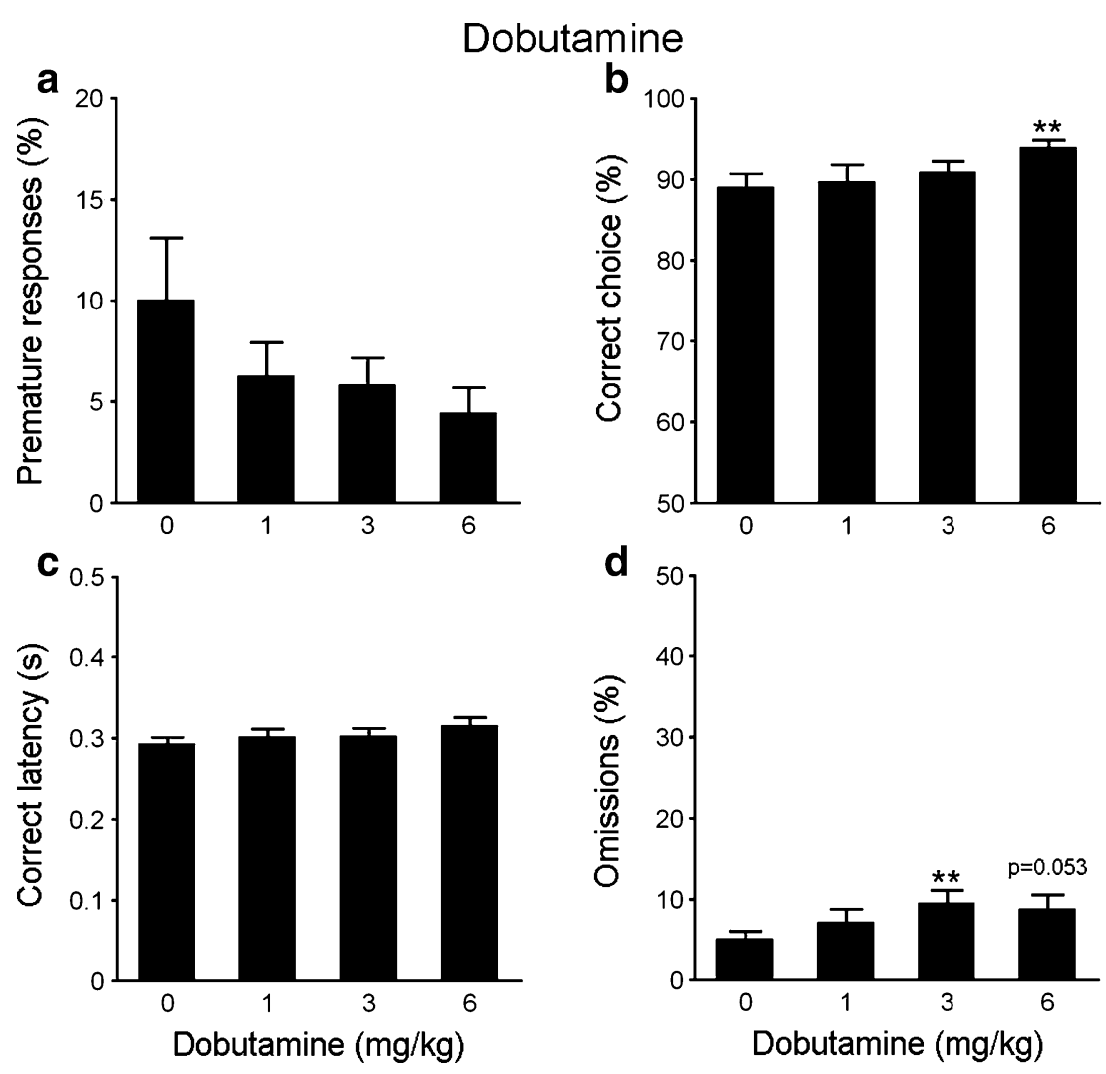

Clenbuterol
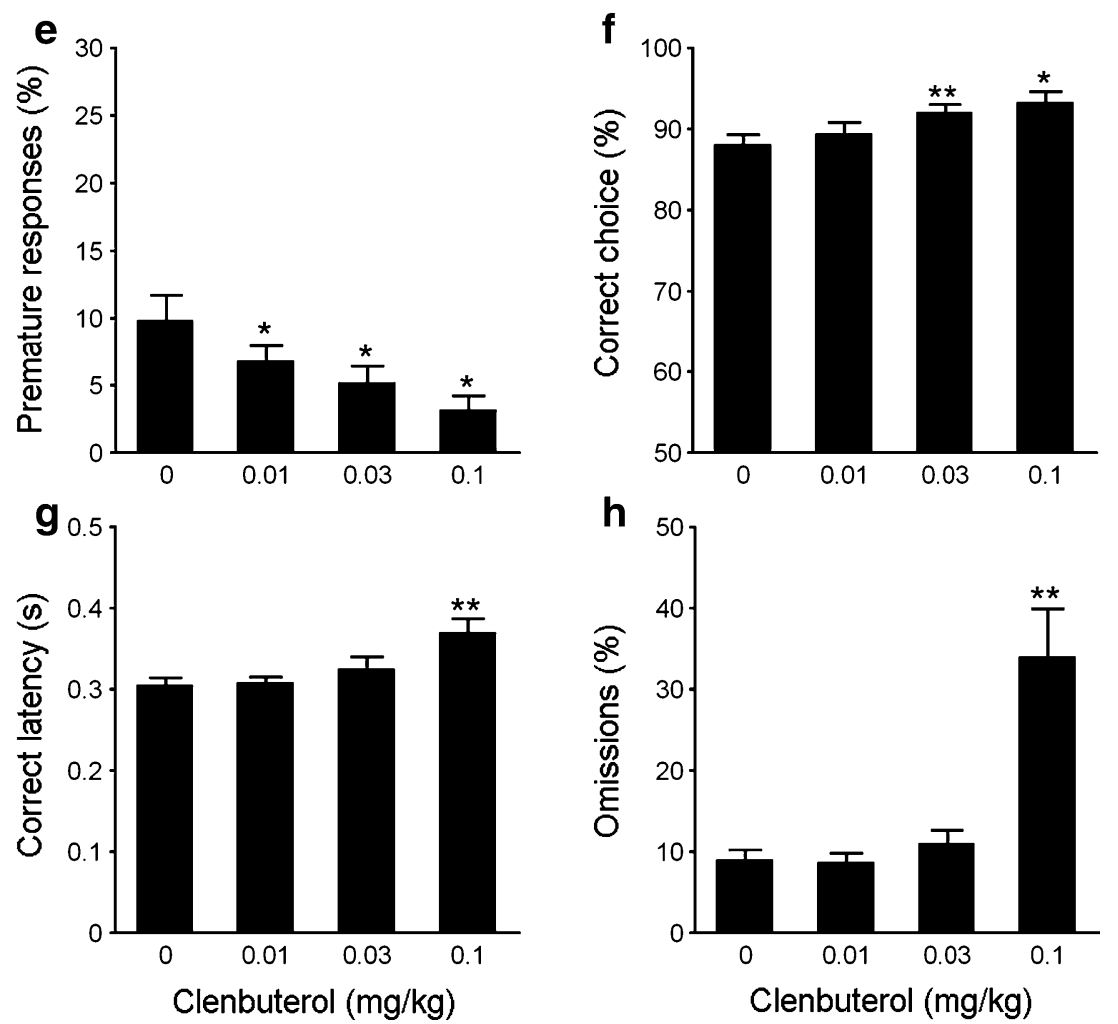

both in humans (Chamberlain et al. 2009) and laboratory animals (Bari et al. 2009; Blondeau and Dellu-Hagedorn
2007; Paterson et al. 2011; Robinson et al. 2008). In keeping with these findings, the selective NA transporter 
inhibitor desipramine also reduced the number of premature responses at $3 \mathrm{mg} / \mathrm{kg}$ without affecting other behavioural parameters in the 5CSRTT, although the effect size was smaller compared to the findings with atomoxetine in this same paradigm (Blondeau and Dellu-Hagedorn 2007; Paterson et al. 2011; Robinson et al. 2008). Collectively, these data thus confirm the beneficial effects of elevating NA transmission on inhibitory response control in addition to other executive functions such as attentional set-shifting, behavioural flexibility and working memory (Berridge et al. 2006; Lapiz et al. 2007; Seu et al. 2009) and this could underlie the therapeutic efficacy of atomoxetine and methylphenidate.

Given the results obtained with methylphenidate and desipramine, subsequent experiments were aimed at further exploring the possible contribution of $\alpha$-adrenoceptors and $\beta$-adrenoceptors to modulate inhibitory response control. In this regard, previous work in rats and monkeys have implicated prefrontal cortical $\alpha 2$-adrenoceptor involvement in the beneficial effects of methylphenidate and atomoxetine on working memory (Arnsten and Dudley 2005; Gamo et al. 2010). To this aim, we tested the effects of phenylephrine, clonidine and isoprenaline. Whereas all of these compounds seemed effective in reducing premature responding, this only appeared to occur at doses that also strongly affected other behavioural parameters reflecting task performance, hampering a straightforward interpretation of these findings. Most prominently, the doses of these compounds reducing premature responding also increased the errors of omission and lengthened response latencies. These observations indicate that the effects on inhibitory response control may be secondary to general behavioural changes, e.g. somatomotor-suppressive effects or altered motivation. On the other hand, the observation that the highest dose isoprenaline increased the omissions and the response latencies but not premature responding might argue against such an interpretation. Our current findings are supported by previous studies, in which direct adrenoceptor agonists have been reported to lead to general behavioural alterations including lengthening of response latencies and increments in response omissions in instrumental behaviour (for example see, Jentsch et al. 2009; Mair et al. 2005; Marrs et al. 2005). More relevant to our findings, the $\alpha 2$-adrenoceptor agonists dexmedetomidine and guanfacine were also found to decrease premature responding in the 5CSRTT at doses that simultaneously increased omission rates (Ruotsalainen et al. 1997; Sirvio et al. 1994) or lengthened latencies to collect food reward (Milstein et al. 2007). Thus, consistent with these observations, a similar behavioural profile was obtained with clonidine in the current study. Although we did not test the lower doses of clonidine, previous work employing such lower doses in a different instrumental behaviour task reveals that the therapeutic window of this compound is narrow and associated with response rate suppressive effects (Dekeyne and Millan 2006).

The beneficial effects of $\alpha 2$-adrenoceptor agonists such as clonidine and guanfacine on prefrontal cortical cognitive functions in preclinical as well as clinical models are thought to be primarily mediated through postsynaptic $\alpha 2$ adrenoceptor activation in the prefrontal cortex (Arnsten 2000; Arnsten et al. 2007). By contrast, presynaptic $\alpha 2-$ adrenoceptor activation is well known to decrease NA transmission (for review see, Berridge and Waterhouse 2003). In addition, $\alpha 2$-adrenoceptor agonists also have strong hypnotic/sedative effects that are presumably mediated in the basal forebrain, locus coeruleus and thalamus (e.g. Berridge and Foote 1996; Buzsaki et al. 1991; Mizobe et al. 1996). Since all compounds were administered peripherally, it is at present difficult to disentangle the effects of clonidine on prefrontal cortical cognitive function from its somatomotor effects as this would require intracranial administration approach. Thus, while clonidine seemed to improve inhibitory response control consistent with earlier data (Milstein et al. 2007; Ruotsalainen et al. 1997; Sirvio et al. 1994) and the clinical therapeutic efficacy of $\alpha 2$ adrenoceptor agonists (Arnsten et al. 2007), central actions of clonidine on sedation/hypnosis are difficult to rule out. In contrast to the effects of clonidine on inhibitory response control, increasing activity at $\alpha 2$-adrenoceptors did not improve visuospatial attention contrasting earlier findings (Berridge et al. 2006; Jentsch et al. 2009; Paine et al. 2007; Sagvolden 2006). However, in the current study, animals were tested under standard task conditions with presumably "optimal" levels of attentional performance and noradrenergic tone. In this regard, there are indications that the beneficial effects of an elevated noradrenergic tone might particularly become apparent under conditions of poor performance or lower baseline noradrenergic tone (Jentsch and Anzivino 2004; Jentsch et al. 2009; Milstein et al. 2007).

The effects of phenylephrine are partly in line with previous data demonstrating that the $\alpha 1$-adrenoceptor agonist St-587 improved both inhibitory response control and visuospatial attention (Puumala et al. 1997). These beneficial effects of St587 on visuospatial attention and not inhibitory response control could be antagonized by the $\alpha 1$-adrenoceptor antagonist prazosin. This suggests particular involvement of these receptor subtypes in attention, for instance by their role in increasing vigilance (Sirvio and MacDonald 1999) and is consistent with the view that $\alpha 1$-adrenoceptor activation enhances the signal-to-noise ratio and tunes processing of sensory information through subcortical and sensory cortical regions (for reviews see, Arnsten 2000; Berridge and Waterhouse 2003). Accordingly, phenylephrine improved accurate choice, albeit separate post hoc comparisons on the high-dose phenylephrine $(3.0 \mathrm{mg} / \mathrm{kg})$ failed to reach statistical significance $(p=0.063)$. The effects of phenylephrine on 
premature responding occurred in concert with effects on response latencies and omission rate and may therefore will be secondary to its effects on somatomotor activity.

In addition to the well-known involvement of $\beta$ adrenoceptors in memory consolidation processes (for review see, Sara 2009), until now few studies have examined the role of these receptors in executive cognitive functioning, namely working memory. Inasmuch one can draw conclusions from these initial studies, they suggest an opposing modulatory role of $\beta 1$-adrenoceptors and $\beta 2$-adrenoceptors in working memory. While a $\beta 1$-adrenoceptor agonist deteriorates working memory (Ramos et al. 2005), a $\beta 2$-adrenoceptor agonist was found to improve working memory performance (Ramos et al. 2008). Interestingly, recent work showed that the non-selective $\beta$-adrenoceptor antagonist propanolol attenuated the detrimental effects of methylphenidate on premature responding in the 5CSRTT (Milstein et al. 2010). This suggests that methylphenidate impairs inhibitory response control partly through $\beta$-adrenoceptor activation at a dose elevating both NA and DA transmission. To our knowledge, the present study is the first reporting on the behavioural effects of $\beta$-adrenoceptor agonists in the 5CSRTT.

Whereas the non-selective $\beta$-adrenoceptor agonist isoprenaline did reduce premature responding at $0.3 \mathrm{mg} / \mathrm{kg}$, this same dose simultaneously increased omission rate and response latencies comparable to the effects of the $\alpha$-adrenoceptor agonists hampering a straightforward interpretation of these data. Importantly, the present data indicate that clenbuterol, a preferential $\beta 2$-adrenoceptor agonist with approximately tenfold higher affinity for $\beta 2$-adrenoceptors over $\beta 1$ adrenoceptors (Baker 2010), dose dependently decreased premature responding at doses that did not significantly alter the measures of somatomotor activity. Moreover, in contrast to the high-dose clenbuterol, the intermediate $0.03 \mathrm{mg} / \mathrm{kg}$ dose improved visuospatial attention by increasing accurate choice without simultaneous deteriorative effects on omissions or response latencies (Fig. 5f). Thus, in extension to beneficial effects on working memory (Ramos et al. 2008), enhancing the tone at $\beta 2$-adrenoceptors also improved inhibitory response control. An important point of consideration is that in addition to the beneficial behavioural effects of particularly clenbuterol observed here, $\beta 2$-adrenoceptors and also $\beta 1$-adrenoceptors are heavily implicated in cardiac function (Brodde and Michel 1999). Indeed, clenbuterol has been shown to exert myotoxic and potent haemodynamic effects in rats starting at doses of $0.1 \mathrm{mg} / \mathrm{kg}$ (Burniston et al. 2002; Sillence et al. 1993). Although in the current study, lower doses of clenbuterol were employed $(0.01$ and $0.03 \mathrm{mg} / \mathrm{kg}$ ) we cannot entirely rule out that these same doses affected cardiac function.

Similar to clenbuterol, the $\beta 1$-adrenoceptor agonist dobutamine increased visuospatial attention. Nonetheless, this effect was only observed at the highest dose of $6.0 \mathrm{mg} / \mathrm{kg}$.
Although dobutamine has an approximately tenfold higher affinity for $\beta 1$-adrenoceptors over $\beta 2$-adrenoceptors (Williams and Bishop 1981), it is possible that at this dose the beneficial effects of this drug on visuospatial attention are mediated through $\beta 2$-adrenoceptor activation (Baker 2010; Makhay and O'Donnell 1999). At the same time, it should be noted that these beneficial effects on attention were not accompanied by significant improvements of inhibitory control. Thus, whereas $\beta 1$-adrenoceptor activation was previously found to impair working memory (Ramos et al. 2005), we did not find evidence for similar effects on attention and inhibitory response control. Collectively, the observation that dobutamine and clenbuterol improved visuospatial attention is consonant with the notion that similar to $\alpha 1$-adrenoceptor activation (see above), enhancing $\beta$-adrenoceptor activity tunes information processing presumably via subcortical and sensory cortical mechanisms (Arnsten 2000; Berridge and Waterhouse 2003).

Our understanding of the contribution of different $\beta$ adrenoceptors in inhibitory response control is limited as yet. Altogether, the present experiments with $\beta$-adrenoceptor agonists further strengthen the notion of $\beta 2$-adrenoceptor and to a lesser extent $\beta 1$-adrenoceptor improvement of prefrontal executive function and in particular inhibitory response control and visuospatial attention. In this respect, it is of interest to note that intracranial clenbuterol injections into the prefrontal cortex ameliorated working memory performance in rats implicating a functional role for $\beta 2$ adrenoceptors in this brain region in prefrontal function (Ramos et al. 2008). The current observations with $\beta$ adrenoceptor agonists are somewhat at odds with the single other study in this area reporting that propanolol attenuates the detrimental effects of methylphenidate on inhibitory response control (Milstein et al. 2010). Evidence from that study suggests subcortical $\beta$-adrenoceptor modulation of DA in the effects of methylphenidate, since cortical NA depletion did not attenuate the effects methylphenidate. Clearly, future studies including the effects of selective $\beta$ adrenoceptor antagonists and employing intracranial approaches are warranted to further unravel this.

In summary, the present data extend previous findings and show that indirect as well as direct adrenoceptor agonists improve inhibitory response control in the 5CSRTT. Although the observed inhibitory effects of most direct $\alpha$-adrenoceptor and $\beta$-adrenoceptor agonists on impulsive action cannot be interpreted unambiguously, our findings with the $\beta 2$-adrenoceptor agonist clenbuteroland to a lesser extent the $\beta 1$-adrenoceptor agonist dobutamine - are consistent with a prominent role of noradrenergic neurotransmission in inhibitory response control. This corroborates the notion that the central noradrenergic system is involved in optimizing behavioural responses including executive cognitive functioning (for reviews, see, 
e.g. Aston-Jones and Cohen 2005; Sara 2009) and particularly points to a role of $\beta 2$-adrenoceptors therein.

Acknowledgements The authors wish to thank Mieke C.W. Janssen for excellent technical assistance.

Open Access This article is distributed under the terms of the Creative Commons Attribution Noncommercial License which permits any noncommercial use, distribution, and reproduction in any medium, provided the original author(s) and source are credited.

\section{References}

Arnsten AF (2000) Through the looking glass: differential noradrenergic modulation of prefrontal cortical function. Neural Plast 7:133-146

Arnsten AF, Dudley AG (2005) Methylphenidate improves prefrontal cortical cognitive function through alpha2 adrenoceptor and dopamine D1 receptor actions: relevance to therapeutic effects in Attention Deficit Hyperactivity Disorder. Behav Brain Funct 1:2

Arnsten AF, Scahill L, Findling RL (2007) alpha2-Adrenergic receptor agonists for the treatment of attention-deficit/hyperactivity disorder: emerging concepts from new data. J Child Adolesc Psychopharmacol 17:393-406

Aron AR, Poldrack RA (2005) The cognitive neuroscience of response inhibition: relevance for genetic research in attentiondeficit/hyperactivity disorder. Biol Psychiatry 57:1285-1292

Aston-Jones G, Bloom FE (1981) Norepinephrine-containing locus coeruleus neurons in behaving rats exhibit pronounced responses to non-noxious environmental stimuli. J Neurosci 1:887-900

Aston-Jones G, Cohen JD (2005) An integrative theory of locus coeruleus-norepinephrine function: adaptive gain and optimal performance. Annu Rev Neurosci 28:403-450

Aston-Jones G, Rajkowski J, Cohen J (1999) Role of locus coeruleus in attention and behavioral flexibility. Biol Psychiatry 46:13091320

Baker JG (2010) The selectivity of $\beta$-adrenoceptor agonists at human $\beta 1-, \beta 2$ - and $\beta 3$-adrenoceptors. Brit J Pharmacol 160:1048-1061

Bari A, Dalley JW, Robbins TW (2008) The application of the 5-choice serial reaction time task for the assessment of visual attentional processes and impulse control in rats. Nat Protoc 3:759-767

Bari A, Eagle DM, Mar AC, Robinson ES, Robbins TW (2009) Dissociable effects of noradrenaline, dopamine, and serotonin uptake blockade on stop task performance in rats. Psychopharmacology (Berl) 205:273-283

Barkley RA (1997) Behavioral inhibition, sustained attention, and executive functions: constructing a unifying theory of ADHD. Psychol Bull 121:65-94

Berridge CW, Foote SL (1996) Enhancement of behavioral and electroencephalographic indices of waking following stimulation of noradrenergic beta-receptors within the medial septal region of the basal forebrain. J Neurosci 16:6999-7009

Berridge CW, Waterhouse BD (2003) The locus coeruleus-noradrenergic system: modulation of behavioral state and state-dependent cognitive processes. Brain Res Rev 42:33-84

Berridge CW, Devilbiss DM, Andrzejewski ME, Arnsten AF, Kelley AE, Schmeichel B, Hamilton C, Spencer RC (2006) Methylphenidate preferentially increases catecholamine neurotransmission within the prefrontal cortex at low doses that enhance cognitive function. Biol Psychiatry 60:1111-1120

Blondeau C, Dellu-Hagedorn F (2007) Dimensional analysis of ADHD subtypes in rats. Biol Psychiatry 62:687-693

Brodde OE, Michel MC (1999) Adrenergic and muscarinic receptors in the human heart. Pharmacol Rev 51:651-690
Burniston JG, Ng Y, Clark WA, Colyer J, Tan LB, Goldspink DF (2002) Myotoxic effects of clenbuterol in the rat heart and soleus muscle. J Appl Physiol 93:1824-1832

Buzsaki G, Kennedy B, Solt VB, Ziegler M (1991) Noradrenergic control of thalamic oscillation: the role of alpha-2 receptors. Eur J Neurosci 3:222-229

Chamberlain SR, Del CN, Dowson J, Muller U, Clark L, Robbins TW, Sahakian BJ (2007) Atomoxetine improved response inhibition in adults with attention deficit/hyperactivity disorder. Biol Psychiatry 62:977-984

Chamberlain SR, Hampshire A, Muller U, Rubia K, Del CN, Craig K, Regenthal R, Suckling J, Roiser JP, Grant JE, Bullmore ET, Robbins TW, Sahakian BJ (2009) Atomoxetine modulates right inferior frontal activation during inhibitory control: a pharmacological functional magnetic resonance imaging study. Biol Psychiatry 65:550-555

Chudasama Y, Passetti F, Rhodes SE, Lopian D, Desai A, Robbins TW (2003) Dissociable aspects of performance on the 5-choice serial reaction time task following lesions of the dorsal anterior cingulate, infralimbic and orbitofrontal cortex in the rat: differential effects on selectivity, impulsivity and compulsivity. Behav Brain Res 146:105-119

Cole BJ, Robbins TW (1987) Amphetamine impairs the discriminative performance of rats with dorsal noradrenergic bundle lesions on a 5-choice serial reaction time task: new evidence for central dopaminergic-noradrenergic interactions. Psychopharmacology (Berl) 91:458-466

Dekeyne A, Millan MJ (2006) Discriminative stimulus properties of the selective and highly potent alpha2-adrenoceptor agonist, S18616, in rats: mediation by the alpha2A subtype, and blockade by the atypical antidepressants, mirtazapine and mianserin. Neuropharmacology 51:718-726

Devilbiss DM, Berridge CW (2006) Low-dose methylphenidate actions on tonic and phasic locus coeruleus discharge. J Pharmacol Exp Ther 319:1327-1335

Eagle DM, Bari A, Robbins TW (2008) The neuropsychopharmacology of action inhibition: cross-species translation of the stop-signal and go/no-go tasks. Psychopharmacology (Berl) 199:439-456

Foote SL, Morrison JH (1987) Extrathalamic modulation of cortical function. Annu Rev Neurosci 10:67-95

Foote SL, Aston-Jones G, Bloom FE (1980) Impulse activity of locus coeruleus neurons in awake rats and monkeys is a function of sensory stimulation and arousal. Proc Natl Acad Sci USA 77:3033-3037

Gamo NJ, Wang M, Arnsten AF (2010) Methylphenidate and atomoxetine enhance prefrontal function through $\alpha 2$-adrenergic and dopamine D1 receptors. J Am Acad Child Adolesc Psychiatry 49:1011-1023

Gerasimov MR, Franceschi M, Volkow ND, Gifford A, Gatley SJ, Marsteller D, Molina PE, Dewey SL (2000) Comparison between intraperitoneal and oral methylphenidate administration: a microdialysis and locomotor activity study. J Pharmacol ExpTher 295:51-57

Harrison AA, Everitt BJ, Robbins TW (1997) Central 5-HT depletion enhances impulsive responding without affecting the accuracy of attentional performance: interactions with dopaminergic mechanisms. Psychopharmacology (Berl) 133:329-342

Jentsch JD, Anzivino LA (2004) A low dose of the alpha2 agonist clonidine ameliorates the visual attention and spatial working memory deficits produced by phencyclidine administration to rats. Psychopharmacology (Berl) 175:76-83

Jentsch JD, Aarde SM, Seu E (2009) Effects of atomoxetine and methylphenidate on performance of a lateralized reaction time task in rats. Psychopharmacology (Berl) 202:497-504

Jodo E, Chiang C, Aston-Jones G (1998) Potent excitatory influence of prefrontal cortex activity on noradrenergic locus coeruleus neurons. Neuroscience 83:63-80 
Kuczenski R, Segal DS (1997) Effects of methylphenidate on extracellular dopamine, serotonin, and norepinephrine: comparison with amphetamine. J Neurochem 68:2032-2037

Lapiz MD, Bondi CO, Morilak DA (2007) Chronic treatment with desipramine improves cognitive performance of rats in an attentional set-shifting test. Neuropsychopharmacology 32:10001010

Mair RD, Zhang Y, Bailey KR, Toupin MM, Mair RG (2005) Effects of clonidine in the locus coeruleus on prefrontal- and hippocampaldependent measures of attention and memory in the rat. Psychopharmacology (Berl) 181:280-288

Makhay MM, O'Donnell JM (1999) Effects of antidepressants in rats trained to discriminate the beta-2 adrenergic agonist clenbuterol. Pharmacol Biochem Behav 63:319-324

Marrs W, Kuperman J, Avedian T, Roth RH, Jentsch JD (2005) Alpha2 adrenoceptor activation inhibits phencyclidine-induced deficits of spatial working memory in rats. Neuropsychopharmacology 30:1500-1510

Milstein JA, Lehmann O, Theobald DE, Dalley JW, Robbins TW (2007) Selective depletion of cortical noradrenaline by antidopamine $\beta$-hydroxylase-saporin impairs attentional function and enhances the effects of guanfacine in the rat. Psychopharmacology (Berl) 190:51-63

Milstein JA, Dalley JW, Robbins TW (2010) Methylphenidateinduced impulsivity: pharmacological antagonism by $\beta$ adrenoreceptor blockade. J Psychopharmacol 24:309-321

Mizobe T, Maghsoudi K, Sitwala K, Tianzhi G, Ou J, Maze M (1996) Antisense technology reveals the alpha2A adrenoceptor to be the subtype mediating the hypnotic response to the highly selective agonist, dexmedetomidine, in the locus coeruleus of the rat. $\mathrm{J}$ Clin Invest 98:1076-1080

Munzar P, Goldberg SR (1999) Noradrenergic modulation of the discriminative-stimulus effects of methamphetamine in rats. Psychopharmacology (Berl) 143:293-301

Navarra R, Graf R, Huang Y, Logue S, Comery T, Hughes Z, Day M (2008) Effects of atomoxetine and methylphenidate on attention and impulsivity in the 5-choice serial reaction time test. Prog Neuropsychopharmacol Biol Psychiatry 32:34 41

O'Donnell JM (1990) Behavioral effects of beta adrenergic agonists and antidepressant drugs after down-regulation of beta-2 adrenergic receptors by clenbuterol. J Pharmacol Exp Ther 254:147-157

Paine TA, Tomasiewicz HC, Zhang K, Carlezon WA Jr (2007) Sensitivity of the five-choice serial reaction time task to the effects of various psychotropic drugs in sprague-dawley rats. Biol Psychiatry 62:687-693

Paterson NE, Ricciardi J, Wetzler C, Hanania T (2011) Sub-optimal performance in the 5-choice serial reaction time task in rats was sensitive to methylphenidate, atomoxetine and d-amphetamine, but unaffected by the COMT inhibitor tolcapone. Neurosci Res 69:41-50

Pattij T, Vanderschuren LJ (2008) The neuropharmacology of impulsive behaviour. Trends Pharmacol Sci 29:192-199

Pattij T, Janssen MC, Vanderschuren LJ, Schoffelmeer AN, van Gaalen MM (2007) Involvement of dopamine D(1) and D (2) receptors in the nucleus accumbens core and shell in inhibitory response control. Psychopharmacology (Berl) 191:587-598

Puumala T, Ruotsalainen S, Jakala P, Koivisto E, Riekkinen P Jr, Sirvio J (1996) Behavioral and pharmacological studies on the validation of a new animal model for attention deficit hyperactivity disorder. Neurobiol Learn Mem 66:198-211

Puumala T, Riekkinen P Sr, Sirvio J (1997) Modulation of vigilance and behavioral activation by alpha-1 adrenoceptors in the rat. Pharmacol Biochem Behav 56:705-712

Ramos BP, Colgan L, Nou E, Ovadia S, Wilson SR, Arnsten AF (2005) The beta-1 adrenergic antagonist, betaxolol, improves working memory performance in rats and monkeys. Biol Psychiatry 58:894-900

Ramos BP, Colgan LA, Nou E, Arnsten AF (2008) Beta2 adrenergic agonist, clenbuterol, enhances working memory performance in aging animals. Neurobiol Aging 29:1060-1069

Robbins TW (2002) The 5-choice serial reaction time task: behavioural pharmacology and functional neurochemistry. Psychopharmacology (Berl) 163:362-380

Robinson ES, Eagle DM, Mar AC, Bari A, Banerjee G, Jiang X, Dalley JW, Robbins TW (2008) Similar effects of the selective noradrenaline reuptake inhibitor atomoxetine on three distinct forms of impulsivity in the rat. Neuropsychopharmacology 33:1028-1037

Rothman RB, Baumann MH (2003) Monoamine transporters and psychostimulant drugs. Eur J Pharmacol 479:23-40

Ruotsalainen S, Haapalinna A, Riekkinen PJ Sr, Sirvio J (1997) Dexmedetomidine reduces response tendency, but not accuracy of rats in attention and short-term memory tasks. Pharmacol Biochem Behav 56:31-40

Sagvolden T (2006) The alpha-2A adrenoceptor agonist guanfacine improves sustained attention and reduces overactivity and impulsiveness in an animal model of Attention-Deficit/ Hyperactivity Disorder (ADHD). Behav Brain Funct 2:4147

Sara SJ (2009) The locus coeruleus and noradrenergic modulation of cognition. Nat Rev Neurosci 10:211-223

Sara SJ, Herve-Minvielle A (1995) Inhibitory influence of frontal cortex on locus coeruleus neurons. Proc Natl Acad Sci USA 92:6032-6036

Sara SJ, Vankov A, Herve A (1994) Locus coeruleus-evoked responses in behaving rats: a clue to the role of noradrenaline in memory. Brain Res Bull 35:457-465

Seu E, Lang A, Rivera RJ, Jentsch JD (2009) Inhibition of the norepinephrine transporter improves behavioral flexibility in rats and monkeys. Psychopharmacology (Berl) 202:505519

Sillence MN, Hunter RA, Pegg GG, Brown L, Matthews ML, Magner T, Sleeman M, Lindsay DB (1993) Growth, nitrogen metabolism, and cardiac responses to clenbuterol and ketoclenbuterol in rats and underfed cattle. J Anim Sci 71:2942-2951

Sirvio J, MacDonald E (1999) Central alpha1-adrenoceptors: their role in the modulation of attention and memory formation. Pharmacol Ther 83:49-65

Sirvio J, Mazurkiewicz M, Haapalinna A, Riekkinen P Jr, Lahtinen H, Riekkinen PJ (1994) The effects of selective alpha-2 adrenergic agents on the performance of rats in a 5-choice serial reaction time task. Brain Res Bull 35:451-455

Sonuga-Barke EJ (2005) Causal models of attention-deficit/hyperactivity disorder: from common simple deficits to multiple developmental pathways. Biol Psychiatry 57:1231-1238

Sun H, Green TA, Theobald DE, Birnbaum SG, Graham DL, Zeeb FD, Nestler EJ, Winstanley CA (2010) Yohimbine increases impulsivity through activation of cAMP response element binding in the orbitofrontal cortex. Biol Psychiatry 67:649656

Swann AC, Birnbaum D, Jagar AA, Dougherty DM, Moeller FG (2005) Acute yohimbine increases laboratory-measured impulsivity in normal subjects. Biol Psychiatry 57:1209-1211

Valera EM, Faraone SV, Murray KE, Seidman LJ (2007) Meta-analysis of structural imaging findings in attention-deficit/hyperactivity disorder. Biol Psychiatry 61:1361-1369

Van den Bergh FS, Bloemarts E, Chan JS, Groenink L, Olivier B, Oosting RS (2006) Spontaneously hypertensive rats do not predict symptoms of attention-deficit hyperactivity disorder. Pharmacol Biochem Behav 83:380-390

Van Gaalen MM, Brueggeman RJ, Bronius PF, Schoffelmeer AN, Vanderschuren LJ (2006a) Behavioral disinhibition requires 
dopamine receptor activation. Psychopharmacology (Berl) 187:73-85

Van Gaalen MM, van Koten R, Schoffelmeer AN, Vanderschuren LJ (2006b) Critical involvement of dopaminergic neurotransmission in impulsive decision making. Biol Psychiatry 60:66-73
Williams RS, Bishop T (1981) Selectivity of dobutamine for adrenergic receptor subtypes: in vitro analysis by radioligand binding. J Clin Invest 67:1703-1711

Winstanley CA, Eagle DM, Robbins TW (2006) Behavioral models of impulsivity in relation to ADHD: translation between clinical and preclinical studies. Clin Psychol Rev 26:379-395 